\title{
DETERMINING IMPORTANT FACTORS OF ARITHMETIC SKILLS AMONG NEWBORN BABIES' AT MALAYSIAN TASKA USING ARTIFICIAL NEURAL NETWORK
}

\author{
Azrul Fazwan Kharuddin', Saadi Ahmad Kamaruddin², Muhamad Naim Kamari ${ }^{3}$, \\ Zaida Mustafa ${ }^{4}$, Norazura Azid ${ }^{5}$ \\ Department of Computational and Theoretical Sciences, Kulliyyah of Science, International \\ Islamic University Malaysia (IIUM), Malaysia ${ }^{1}$, \\ Faculty of Business, Economics and Accounting, HELP University, Malaysia ${ }^{2}$ \\ Faculty of Culinary \& Tourism, UNITAR International University, Malaysia ${ }^{3}$ \\ Faculty of Graduate School of Education, UNITAR International University, Malaysia ${ }^{4}$, \\ SMK Sungai Soi, Kuantan Pahang, Malaysia ${ }^{5}$ \\ azrulfazwan@yahoo.com ${ }^{1}$, adi8585@yahoo.com ${ }^{2}$, naimkamari@unitar.my3 \\ zaida@unitar.my ${ }^{4}$,zurazid@yahoo.com ${ }^{5}$
}

\begin{abstract}
In Malaysia, most parents prefer to choose registered early childhood learning centers (TASKA), due to their perceptions that the centers are with quality services and well-observed by the government authority. In this quantitative research, the main objective is to identify the best model to represent the contributing factors which influence arithmetic performance among children at registered Malaysian TASKA. Childrens' arithmetic performance in general affect their mental capability and overall personal skills development. This research is significant to determining the important contributing factors which influence newborn babies' mathematical skills. Data was collected using a survey questionnaire. Based on the right sampling method, 376 registered TASKAs in Malaysia were chosen. Among the 458 chosen centers, only 63 centres provide care and education services for children age of 0 to 6 months. Neural network technique was the analysis adapted in order to achive the research objective. In the near future, the research will be extended to the unregistered TASKA in Malaysia, and the fair comparisons will be made with the registered centers.
\end{abstract}

Keywords: TASKA, arithmetic, mathematical skills, model, neural network

\section{INTRODUCTION}

The first three years of childhood is a critical period in child development as a whole. At this stage, babies and trainees need a variety of learning experiences in a quality parenting environment for further development (Field et al., 2013). Throughout these early years of life, children see and investigate scientific measurements of their reality. This learning experience can be explored through interaction and activity relationships at TASKA. An authentic curriculum can provide guidance to educators, how to interact and work with children in TASKA. The guidelines provide opportunities and provide children with learning. While planned activities should be appropriate to the level in which the learning environment is rich, fun and challenging for the development of children (Ozar, 2012). Arithmetic enables youngsters to comprehend their reality outside of school and encourages them develop a strong establishment for achievement in school.

The construction of this paper can be divided into six sections. Section 1 is the introduction part. Section 2 comprises of the related literature to this research. Section 3 regards to data background. Section 4 is pertaining research framework. Section 5 is on the methodology 
adapted in this research. Section 6 is all about the results and discussions. Section 7 is the final part and closure of the paper, which comprises of the conclusion as well as recommendations for enhancement and future work.

\section{LITERATURE REVIEW}

Early childhood demonstrate a characteristic enthusiasm for and happiness regarding science and mathematics. Research prove shows that some time before entering early childcare center immediately investigate and utilize science in any event the natural beginnings and their scientific learning can be very unpredictable and refined (Seo et al., 2004). In play and day by day exercises, early childhood regularly investigate scientific thoughts and procedures; for instance, they sort and order, look at amounts, and notice shapes and examples (Baroody, 2004; Clements et al., 1999; Fuson, 2004; Gelman, 1994; Ginsburg et al., 1998; Piaget \& Inhelder, 1967; Steffe, 2004). Science enables kids to understand the physical and social universes around them, and early childhoods are normally disposed to utilize arithmetic in imaginative and logical. By profiting by such minutes and via precisely arranging an assortment of encounters in view of scientific thoughts, instructors develop and broaden kids' numerical sense and intrigue. Since youthful kids' encounters on a very basic level shape their state of mind toward science, a drawing in and empowering atmosphere for early childhoods' initial experiences with arithmetic is essential (National Council of Teachers of Mathematics, 2000). It is indispensable for early childhoods to create trust in their capacity to comprehend and utilize arithmetic at the end of the day, to consider science to be inside their compass. Furthermore, positive encounters with utilizing arithmetic to take care of issues help early childhoods to create auras, for example, interest, creative energy, adaptability, imagination, and steadiness that add to their future accomplishment all through school (Clements \& Conference Working Group, 2004).

Perceiving and expanding on early childhoods' individual encounters and information are fundamental to compelling early youth science training (Seo \& Ginsburg, 2004; Clements et al., 1999; Copple, 2004; Geary, 1994). While striking similitudes are clear in the numerical issues that premium offspring of various foundations (Ginsburg et al., 2001) it is likewise obvious that early childhoods have changing social, semantic, home, and group encounters on which to manufacture arithmetic learning (Natriello et al., 1990; Han \& Ginsburg, 2001). For instance, number naming is consistent in Asian dialects, for example, Korean (the Korean word for "eleven" is send sick, or "ten one"), while English uses the sporadic word eleven. This distinction seems to make it less demanding for Korean early childhoods to learn or build certain numerical ideas (Miura et al., 1988; Park, 2000). To accomplish value and instructive viability, educators or caregivers must know as much as they can about such contrasts and work to manufacture connects between kids' fluctuating encounters and new learning (Berk \& Winsler, 1995; Heath, 1983; Vygotsky, 1986; Razel \& Eylon, 1990). In arithmetic, as in any information space, students advantage from having an assortment of approaches to comprehend a given idea (Kilpatrick et al., 2001; Bowman et al., 2001). Expanding on kids' individual qualities and learning styles makes arithmetic educational modules and guideline more powerful. For instance, a few kids learn particularly well when instructional materials and methodologies utilize geometry to pass on number ideas (Razel \& Eylon, 1990). Early childhoods' certainty, skill, and enthusiasm for science prosper when new encounters are significant and associated with their earlier information and experience (National Council of Teachers of Mathematics, 2000; Bredekamp \& Rosegrant, 1995). At to start with, early childhoods' comprehension of a numerical idea is just instinctive. Absence of express ideas 
once in a while keeps the kid from making full utilization of earlier information and interfacing it to class arithmetic. In this way, instructors need to discover what early childhoods as of now comprehend and enable them to start to comprehend these things numerically or mathematically.

\section{DATA BACKGROUND}

Based on the respondents' demographic data, pilot studies have been conducted on 20 TASKA covering all categories namely TASKA Government Assistance such as:

a) Pusat Asuhan Permata Negara (PAPN)

b) TASKA Permata Perpaduan (JPNIN)

c) TASKA Permata KEMAS (KEMAS)

d) Yayasan Pembangunan Keluarga Terengganu (YPKT)

e) TASKA for Disabilities (OKU)

f) TASKA at Government Workplace (TTKA) and

g) TASKA Komuniti (TASKOM)

TASKA Without Government Assistance such as:

a) TASKA Institution (TIN)

b) TASKA Home (TDR) and

c) TASKA in the Private Workplace (TTKS).

This study has resulted in a legitimate research instrument and has reasonable reliability.

The actual data of this study was obtained from 458 TASKA covering all categories of TASKA namely government assistance (PAPN, JPNIN, KEMAS, YPKT, OKU, TTKA and TASKOM) and TASKA Without Government Assistance (TIN, TDR and TTKS). In particular, quantitative research data is obtained from 63 centre directors which provide care and education services for children age of 0 to 6 months. Upon more information on the questionnaire, kindly contact the main author since this is regards to confidentiality and copyright matters by Malaysian government.

\section{RESEARCH FRAMEWORK}

TASKA in Malaysia uses the PERMATA curriculum for children aged 0 to 4 years. This curriculum contains 6 areas of study which include:

a) The development of personality, socio-emotion and spirituality (SSK)

b) Development of language skills, communication and early literacy (BKL)

c) Physical development (Physical)

d) The development of the senses and understanding of the world environment (Senses)

e) The development of creativity and aesthetics (Creativity)

f) Early development of mathematics and logical thinking (Math)

Table 1 represents the variables used in this research as well as the explanations of each variable, and Figure 1 illustrates the theoretical framework of this research in order to achive the main objective. 
Table 1: The Variables Used in This Research

\begin{tabular}{|c|c|c|c|c|}
\hline No. & Variable(s) & Parameters & Notation & Type \\
\hline 1. & Dependent & MeanMath & $\begin{array}{l}\text { Mean Score of Early Development of Mathematics } \\
\text { and Logical Thinking variable }\end{array}$ & Continuous \\
\hline 2. & \multirow{5}{*}{ Independent } & MeanPhysical & Mean Score of Physical Development variable & Continuous \\
\hline 3. & & MeanSSK & $\begin{array}{c}\text { Mean Score of Personality, Socio-emotional and } \\
\text { Spirituality Development variable }\end{array}$ & Continuous \\
\hline 4. & & MeanBKL & $\begin{array}{l}\text { Mean Score of Development of Language Skills, } \\
\text { Communication and Early Literacy variable }\end{array}$ & Continuous \\
\hline 5. & & MeanSenses & $\begin{array}{l}\text { Mean Score of Development of the senses and } \\
\text { understanding of the world environment variable }\end{array}$ & Continuous \\
\hline 6. & & MeanCreativity & $\begin{array}{c}\text { Mean Score of Development of Creativity and } \\
\text { Aesthetics variable }\end{array}$ & Continuous \\
\hline
\end{tabular}

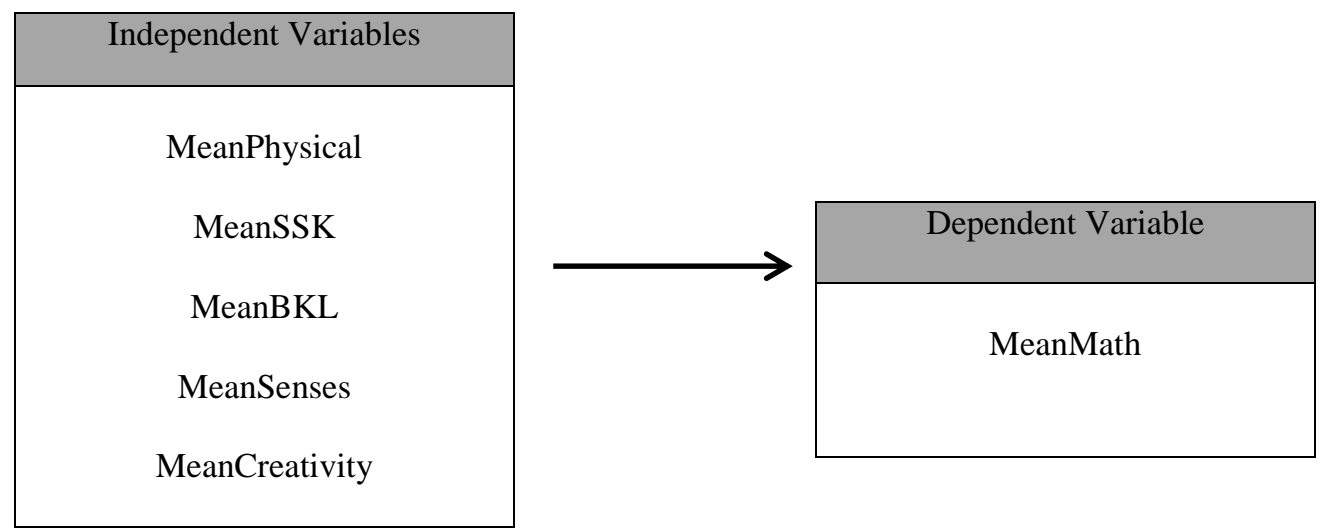

Figure 1: Theoretical Framework

\section{METHODOLOGY}

Artificial neural networks (ANNs) or connectionist systems are computing systems inspired by the biological mechanisms that constitute human brains, which automatically and continuously learn their nature or environment for better understanding and decision making.

A nonlinear model that contains more than one predictor variableneural network is developed in this research. The following model is a neural network model with five predicting variables, $\beta_{1}, \beta_{2}, \beta_{3}, \beta_{4}$ and $\beta_{5}$.

$$
Y=\text { identity }\left(L W^{2,1}\left(\tan \operatorname{sig}\left[\begin{array}{l}
\left(I W_{1}\right)^{1,1} * \beta_{1}+\left(I W_{2}\right)^{1,2} * \beta_{2}+\left(I W_{3}\right)^{1,3} * \beta_{3}+\left(I W_{4}\right)^{1,4} \\
* \beta_{4}+I\left(W_{5}\right)^{1,5} * \beta_{5}+\varepsilon^{1}
\end{array}\right]\right)+\varepsilon^{2}\right)
$$

In this research, we adapted two-layer neural network, with tansig trasfer function in the first layer and purelin transfer function at the second layer. Hyperbolic tangent is the training function used in the hidden layer and identity funcion in the output layer, with MSE equals to 0.0 as the criterion function. In this research, the neural network model is 


$$
\text { MeanMath }=\text { purelin }\left(L W^{2,1}\left(\tan \operatorname{sig}\left[\begin{array}{l}
\left(I W_{1}\right)^{1,1} * \text { MeanPhysical }+\left(I W_{2}\right)^{1,2} * \\
\text { MeanSSK }+\left(I W_{3}\right)^{1,3} * \text { MeanBKL } \\
+\left(I W_{4}\right)^{1,4} * \text { MeanSenses }+\left(I W_{5}\right)^{1,5} * \\
\text { MeanCreativity }+b^{1}
\end{array}\right]\right)+b^{2}\right)
$$

The final model will include only the significant predictors to explain MeanMath.

\section{RESULTS AND DISCUSSIONS}

Figure 2 shows the network architecture used in this research which consist of six hidden nodes in the hidden layer. From Figure 3, it can be seen that the network performed very well where the network residuals scattered mostly on the 0 errors line. The data were partitioned into three different datasets which are 70\% (training), 15\% (validation) and 15\% (testing). The relative error for testing set is only 0.049 .

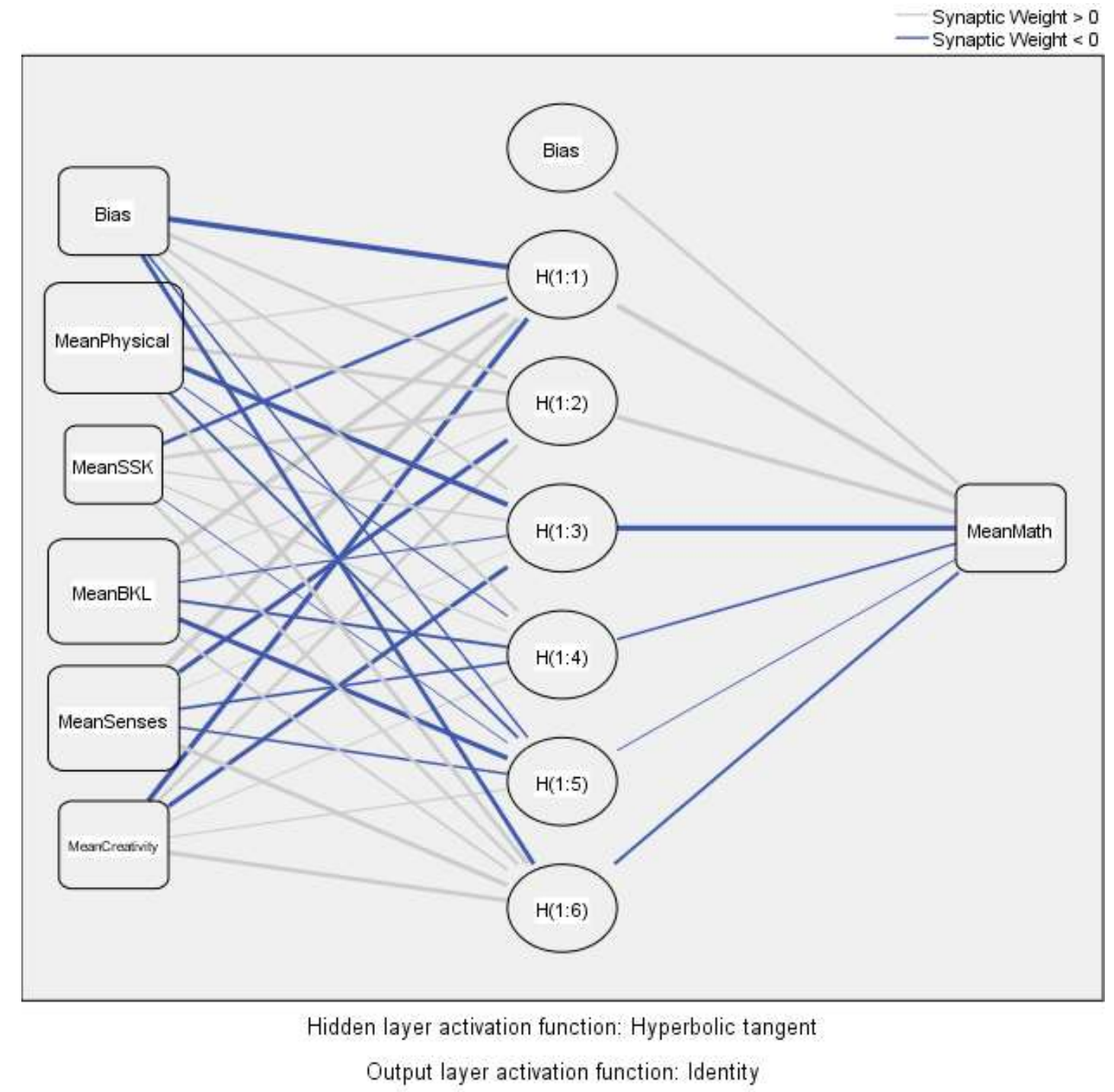

Figure 2: The architecture of neural network model in this research 
Table 2: Parameter Estimates

\begin{tabular}{|c|c|c|c|c|c|c|c|c|}
\hline \multirow{3}{*}{\multicolumn{2}{|c|}{ Predictor }} & \multicolumn{7}{|c|}{ Predicted } \\
\hline & & \multicolumn{6}{|c|}{ Hidden Layer 1} & \multirow{2}{*}{$\begin{array}{c}\text { Output Layer } \\
\text { MeanMath }\end{array}$} \\
\hline & & $\mathrm{H}(1: 1)$ & $\mathrm{H}(1: 2)$ & $\mathrm{H}(1: 3)$ & $\mathrm{H}(1: 4)$ & $\mathrm{H}(1: 5)$ & $\mathrm{H}(1: 6)$ & \\
\hline \multirow{6}{*}{ Input Layer } & (Bias) & -.791 & .337 & .274 & .284 & -.148 & -.434 & \\
\hline & MeanPhysical & .127 & .358 & -.602 & -.067 & -.262 & .419 & \\
\hline & MeanSSK & -.328 & .340 & .143 & .129 & -.014 & .285 & \\
\hline & MeanBKL & .619 & .034 & -.081 & -.270 & -.491 & .252 & \\
\hline & MeanSenses & 1.134 & -.463 & .012 & -.249 & -.172 & .458 & \\
\hline & MeanCreativity & -.548 & .290 & -.450 & .063 & .125 & .446 & \\
\hline \multirow{7}{*}{ Hidden Layer 1} & (Bias) & & & & & & & .296 \\
\hline & $\mathrm{H}(1: 1)$ & & & & & & & .838 \\
\hline & $\mathrm{H}(1: 2)$ & & & & & & & .496 \\
\hline & $\mathrm{H}(1: 3)$ & & & & & & & -.654 \\
\hline & $\mathrm{H}(1: 4)$ & & & & & & & -.196 \\
\hline & $\mathrm{H}(1: 5)$ & & & & & & & -.030 \\
\hline & $\mathrm{H}(1: 6)$ & & & & & & & -.271 \\
\hline
\end{tabular}

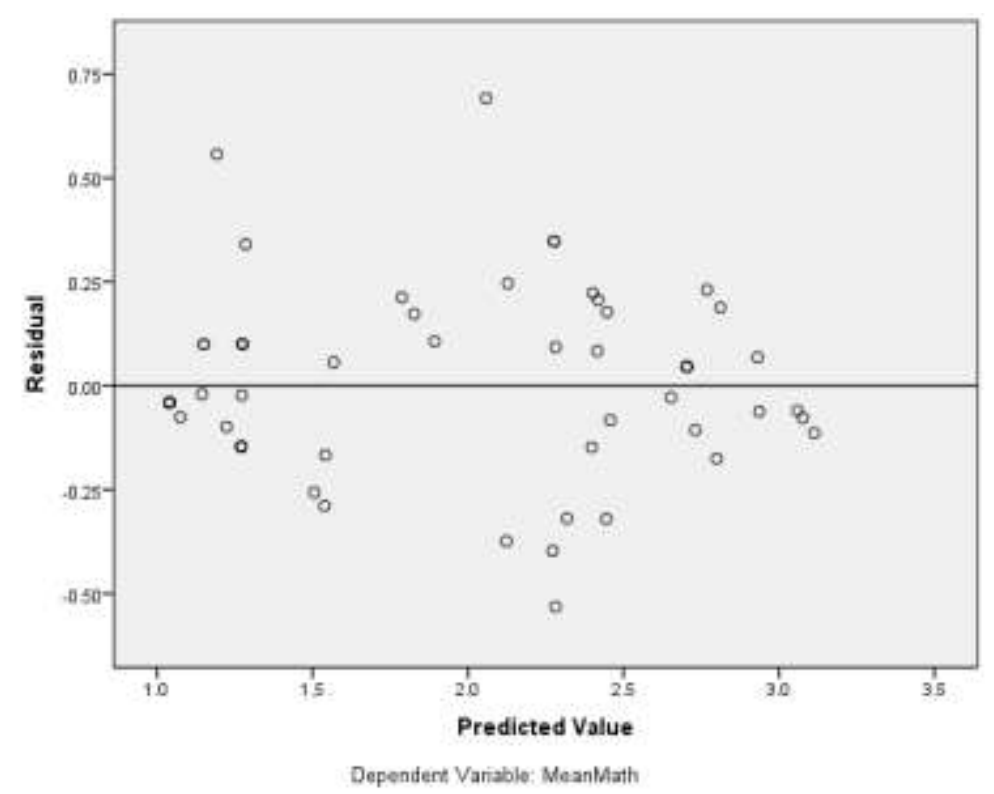

Figure 3: Scattered residuals

From Table 4, it is understandable that the most important variable contribute to total marks is critical control points which is total 100 percent influence. The results can be viewed clearly in Figure 4.

Table 3: Independent Variable Importance

\begin{tabular}{lcc}
\hline & Importance & Normalized Importance \\
\hline MeanPhysical & .283 & $100.0 \%$ \\
\hline MeanSSK & .082 & $29.1 \%$ \\
\hline MeanBKL & .246 & $86.7 \%$ \\
\hline MeanSenses & .248 & $87.4 \%$ \\
\hline MeanCreativity & .141 & $49.8 \%$ \\
\hline
\end{tabular}




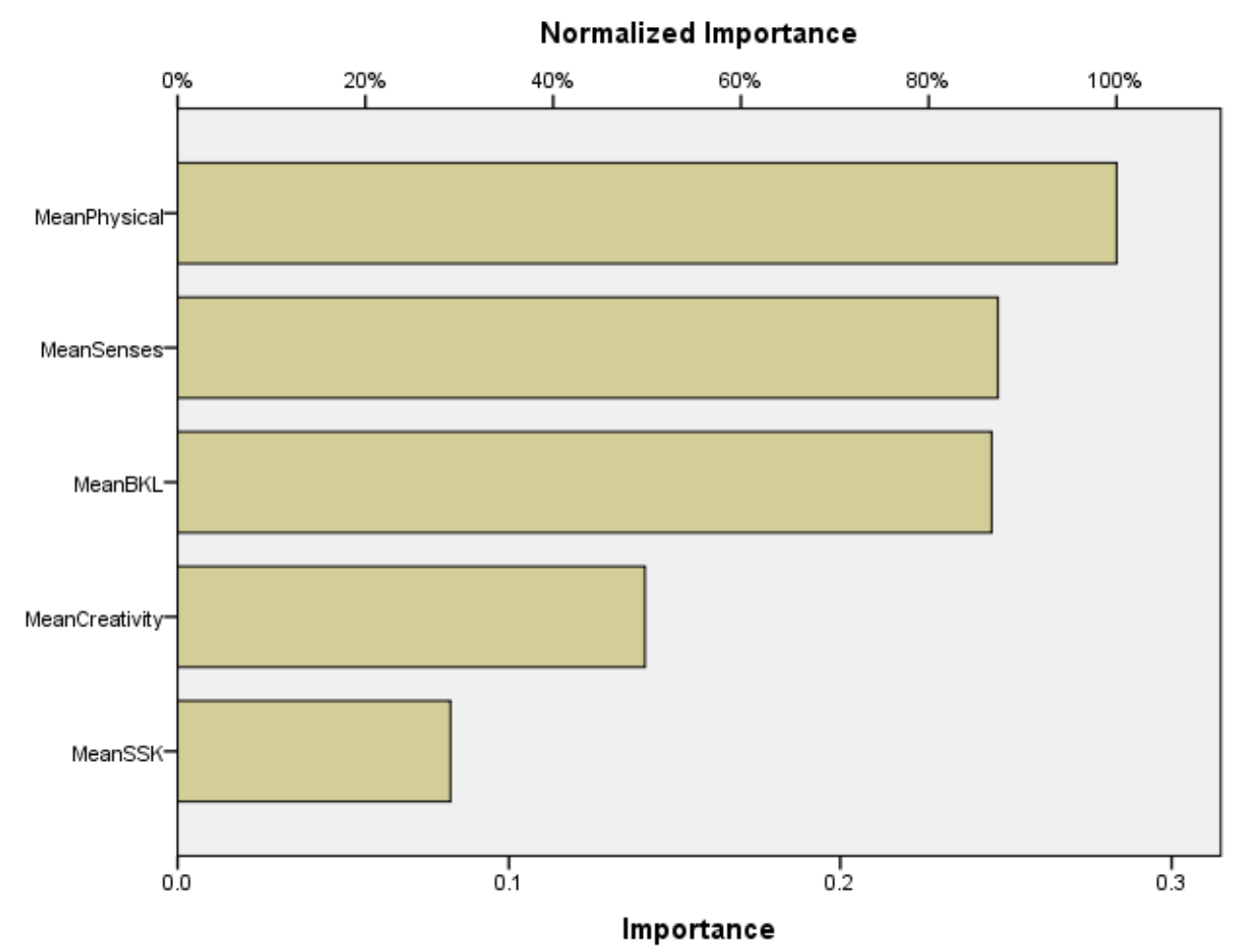

Figure 4: Variables importance levels

\section{CONCLUSIONS}

As a conclusion, we can say that the objective is successfully achived. In order to ensure well development of mathematical and logical thinking among children age on 0 to 6 months, curriculum should focus on these five attibutes accordingly:

i. Physical development variable

ii. Development of the senses and understanding of the world environment variable

iii. Development of language skills, communication and early literacy variable

iv. Development of creativity and aesthetics variable

v. The development of personality, socio-emotion and spirituality

Therefore a proper curriculum need to be revised at TASKAs in order to ensure good reasoning and arithmetic skils for the children of the said age. For future work, the similar approaches shall be ventured to children age groups which are 6-12, 12-24, 24-36, 36-48 months at Malaysian TASKA.

The developed model is signifant towards identifying and measuring the quality of mathematical and logical thinking achievement at TASKA or any other childcare centers around the world. Proper syllabus should be made by the related authorities with respected to the significant attributes in order to affirm good methematical development among children as soon as they are born. 


\section{ACKNOWLEDGEMENT}

Millions of thanks to Jabatan Kebajikan Masyarakat Malaysia (JKMM) for the engagement with this consultancy study on 'Kajian Perkhidmatan TASKA di Malaysia', under the grant No. LTBKS/01/2016. The authors will also declare IIUM \& UNITAR International University staff and students for their support in completing the fieldwork of research. Special gratitudes to the professionals for the construction of the questionnaires, Dr. Zaitol bt Salleh, Mrs. Noraida Bt Ibrahim and Mrs. Umi Hani bt Awang from JKM, Assoc. Prof. Dr. Azhar Adnan from HELP University, as well as Dr. Bustam Kamri from International College of Yayasan Melaka (ICYM).

\section{REFERENCES}

Baroody, A.J. 2004. The role of psychological research in the development of early childhood mathematics standards. In Engaging young children in mathematics: Standards for early childhood mathematics education, eds. D.H. Clements, J. Sarama, \& A.-M. DiBiase, 149-72. Mahwah, NJ: Lawrence Erlbaum.

Berk, L.E., \& A. Winsler. 1995. Scaffolding children's learning: Vygotsky and early childhood education. Washington, DC: NAEYC.

Bowman, B.T., M.S. Donovan, \& M.S. Burns, eds. 2001. Eager to learn: Educating our preschoolers. Washington, DC: National Academy Press.

Bredekamp, S., \& T. Rosegrant. 1995. Reaching potentials: Transforming early childhood curriculum and assessment. Volume 2. Washington, DC: NAEYC.

Clements, D.H., \& Conference Working Group. 2004. Part one: Major themes and recommendations. In Engaging young children in mathematics: Standards for early childhood mathematics education, eds. D.H. Clements, J. Sarama, \& A.-M. DiBiase, 7-76. Mahwah, NJ: Lawrence Erlbaum.

Clements, D.H., S. Swaminathan, M.-A. Hannibal, \& J. Sarama. 1999. Young children's concepts of shape. Journal for Research in Mathematics Education 30: 192-212.

Copple, C.E. 2004. Math curriculum in the early childhood context. In Engaging young children in mathematics: Standards for early childhood mathematics education, eds. D.H. Clements, J. Sarama, \& A.-M. DiBiase, 83-90. Mahwah, NJ: Lawrence Erlbaum.

Field, T., Ezell, S., Nadel, J., Grace, A., Allender, S., \& Siddalingappa, V. (2013). Reciprocal imitation following adult imitation by children with autism. Infant and Child Development, 22(6), 642-648.

Fuson, K.C. 2004. Pre-K to grade 2 goals and standards: Achieving 21st century mastery for all. In Engaging young children in mathematics: Standards for early childhood mathematics education, eds. D.H. Clements, J. Sarama, \& A.-M. DiBiase, 105-48. Mahwah, NJ: Lawrence Erlbaum.

Geary, D.C. 1994. Children's mathematical development: Research and practical applications. Washington, DC: American Psychological Association.

Gelman, R. 1994. Constructivism and supporting environments. In Implicit and explicit knowledge: An educational approach, ed. D. Tirosh, 55-82. Norwood, NJ: Ablex.

Ginsburg, H.P., A. Klein, \& P. Starkey. 1998. The development of children's mathematical thinking: Connecting research with practice. In Handbook of child psychology, Volume 4: Child psychology in practice, eds. W. Damon, I.E. Sigel, \& K.A. Renninger, 401-76. New York: John Wiley \& Sons.

Ginsburg, H.P., S. Pappas, \& K.-H. Seo. 2001. Everyday mathematical knowledge: Asking young children what is developmentally appropriate. In Psychological perspectives on early childhood education: Reframing dilemmas in research and practice, ed. S.L. Golbeck, 181-219. Mahwah, NJ: Lawrence Erlbaum.

Han, Y., \& H.P. Ginsburg. 2001. Chinese and English mathematics language: The relation between linguistic clarity and mathematics performance. Mathematical Thinking and Learning 3: 201-20.

Heath, S.B. 1983. Ways with words: Language, life, and work in communities and classrooms. Cambridge, UK: Cambridge University Press.

Kilpatrick, J., J. Swafford, \& B. Findell. 2001. Adding it up: Helping children learn mathematics. Washington, DC: National Academy Press.

Miura, I.T., C.C. Kim, C.-M. Chang, \& Y. Okamoto. 1988. Effects of language characteristics on children's cognitive representation of number: Cross-national comparisons. Child Development 59: 1445-50.

National Council of Teachers of Mathematics. 2000. Principles and standards for school mathematics. Reston, VA: Author.

Natriello, G., E.L. McDill, \& A.M. Pallas. 1990. Schooling disadvantaged children: Racing against catastrophe. New York: Teachers College Press. 
Özar, M. (2012). Curriculum of Preschool Education: Swedish Approach. International Journal of Business and Social Science, 3(22).

Park, M. 2000. Linguistic influence on numerical development. The Mathematics Educator 10 (1): 19-24.

Piaget, J., and B. Inhelder. 1967. The child's conception of space. New York: W.W. Norton.

Razel, M., \& B.-S. Eylon. 1990. Development of visual cognition: Transfer effects of the Agam program. Journal of Applied Developmental Psychology 11: 459-85.

Seo, K.-H., \& H.P. Ginsburg. 2004. What is developmentally appropriate in early childhood mathematics education? In Engaging young children in mathematics: Standards for early childhood mathematics education, eds. D.H. Clements, J. Sarama, \& A.-M. DiBiase, 91-104. Mahwah, NJ: Lawrence Erlbaum.

Steffe, L.P. 2004. PSSM from a constructivist perspective. In Engaging young children in mathematics: Standards for early childhood mathematics education, eds. D.H. Clements, J. Sarama, \& A.-M. DiBiase, 221-52. Mahwah, NJ: Lawrence Erlbaum.

Vygotsky, L.S. [1934] 1986. Thought and language. Cambridge, MA: MIT Press. 